\title{
BIOGÁS EM ATERROS SANITÁRIOS: COMPARANDO A GERAÇÃO ESTIMADA COM A QUANTIDADE VERIFICADA EM PROJETOS DE MECANISMO DE DESENVOLVIMENTO LIMPO
}

\author{
J. G. J. PEDOTT e A. O. AGUIAR \\ Universidade Nove de Julho - UNINOVE \\ aaguiar@uninove.br
}

Artigo submetido em outubro/2013 e aceito em agosto/2014

DOI: $10.15628 /$ holos.2014.1715

\section{RESUMO}

Os sistemas de captação e queima do biogás de aterros sanitários permitem sua utilização como combustível para geração de energia elétrica ou outros fins energéticos, e geração de créditos de carbono em projetos de Mecanismo de Desenvolvimento Limpo e de venda da energia gerada, essenciais para a viabilidade econômica desses projetos. Com o objetivo de comparar as previsões de geração de biogás em aterros com a produção real, foram estudados dois aterros da cidade de São Paulo. A metodologia de cálculo de estimativa de geração biogás que é objeto de estudo deste trabalho é a aplicada pela Convenção-Quadro das Nações Unidas para as Mudanças Climáticas (United Nations Framework Convention on Climate Change - UNFCCC), chamada ACM0001 nas versões 02 e 13, para calcular as estimativas de captação de biogás para os dois aterros supracitados. A comparação mostrou que a quantidade de gás captada está em média $52 \%$ abaixo da previsão inicial do projeto, e que a versão 13 da metodologia produz resultados mais próximos do real. Entre as outras causas de diferenças que poderiam ser estudadas estão a composição do lixo, os métodos de operação dos aterros e as condições climáticas locais

PALAVRAS-CHAVE: Resíduos Sólidos, Aterro Sanitário, Gás de Efeito Estufa.

\section{BIOGAS IN SANITARY LANDFILLS: COMPARING ESTIMATED GENERATION WITH THE VERIFIED AMOUNT IN CLEAN DEVELOPMENT PROJECTS}

\begin{abstract}
The systems to capture and burn landfill gas allow its use as fuel for generation of electricity or other energy purposes, and generation of carbon credits in projects of the Clean Development Mechanism and sale of the generated energy, essential for the economic viability of these kind of projects. In order to compare the estimates of landfill gas generation with the real production, it was studied the two biggest landfills in the city of São Paulo. The methodology applied for estimating the landfill gas which is object of this work is the one applied by the
\end{abstract}

UNFCCC, called ACM 0001 in its versions n. 02 and 13, to calculate the estimates of the capture landfill gas for both landfills mentioned above. The comparison showed that the amount of landfill gas captured is about $52 \%$ below than the initial estimates in the beginning of the projects, and the version 13 of the ACM0001 is able to produce forecasts closer to the real. Other causes of differences that could be studied are the composition of the solid waste in the landfill, the methods of operation of the landfills and local climatic conditions.

KEYWORDS: Solid Waste, Landfill, Greenhouse Gas. 


\section{INTRODUÇÃO}

O Programa das Nações Unidas pra o Meio Ambiente - UNEP - estima que sejam coletadas anualmente 11,2 bilhões de toneladas de resíduos sólidos em todo o mundo, e a degradação da matéria orgânica nele contido representa algo em torno de $5 \%$ das emissões de gases causadores do efeito estufa (UNEP, 2011).

De acordo com a Pesquisa Nacional de Saneamento Básico - 2008, metade dos mais de cinco mil municípios brasileiros destinam seus resíduos para lixões. Conforme o próprio relatório, tal situação se configura como um cenário de destinação reconhecidamente inadequado, que exige soluções urgentes e estruturais para o setor (IBGE, 2010).

Em todo o mundo, a urgência em se reduzir a concentração atmosférica de gases de efeito estufa provocou a adoção de quadros regulamentares favoráveis para incentivar o setor público e privado a investirem em energias renováveis (ARCADIS Tetraplan, 2010).

Neste contexto, foi criado no âmbito internacional, em 1997, o Protocolo de Quioto, que o Brasil ratificou no ano de 2002. O acordo prevê que as Partes que subscrevem o protocolo adotem programas nacionais de redução de emissões, complementados com os chamados "mecanismos de flexibilização": comércio de emissões, sistema de implementação conjunta e mecanismo de desenvolvimento limpo, como o objetivo de reduzir as emissões globais de gases de efeito estufa. Para os países listados no Anexo I do Protocolo, é estabelecida a meta de redução de $5 \%$ das emissões, tendo como base o ano de 1990 (Brasil, 2005).

Tais mecanismos permitem aos países interessados concretizar as metas de redução das emissões, mantendo os custos de suas ações em níveis toleráveis (JUSTI e MOLITERNO, 2008).

Cabe às Partes que aderiram ao Protocolo de Quioto implementar um sistema nacional de contabilização das emissões de GEE, bem como a quantidade removida por sumidouros, a fim de demonstrar o progresso alcançado no cumprimento de suas metas de redução de emissões. Cabe ainda, às Partes, buscar por transferência de tecnologias ambientalmente seguras e de propriedade pública. Os prazos para os projetos podem ser de no máximo dez anos para projetos de período fixo ou de sete anos para projetos de período renovável. Os projetos são renováveis por no máximo três períodos de sete anos dando um total de vinte e um anos (MCT, 2010).

Neste contexto, o Brasil se destaca no cenário internacional como um importante ator ligado ao Mecanismo de Desenvolvimento Limpo (MDL). Lucas e Melo (2011) destacam o potencial de geração de benefícios para o País e a subutilização de algumas possibilidades, devido a concentração de projetos no Sudeste e a predominância de projetos e biomassa para uso energético próprio. De acordo com a ONU, Brasil ocupa primeira posição em número de projetos e volume de CERs emitidos na América Latina e Caribe, sendo responsável pela redução de 366.263.000 $\mathrm{tCO}_{2} \mathrm{e}$ (toneladas equivalentes de gás carbônico) em 2012, o que corresponde a 44\% do total mundial para o primeiro período de obtenção de créditos (UNEP, 2012).

Dos 204 projetos de MDL registrados em diversos setores no Brasil, 68 são realizados em aterros sanitários. Destes, apenas 7 foram registrados com intuito de geração de energia e outros 12 estão em validação, constituindo-se uma oportunidade promissora para promover a sustentabilidade social e ambiental do desenvolvimento municipal no país, por meio do estímulo 
a uma gestão mais apropriada dos resíduos sólidos urbanos (UNEP, 2012). De acordo com Friberg (2009), os principais benefícios do MDL para o Brasil tem sido sua contribuição na diversificação do sistema energético e na criação de capacidade institucional para governança em carbono. A transferência de tecnologia também é um aspecto importante, e está muito associada, no caso brasileiro, a presença de parceiros internacionais (DECHEZLEPRÊTRE et al, 2009).

Há, ainda, uma grande incerteza no cálculo das emissões geradas por aterros de resíduos: a variedade de processos que ocorre na massa de resíduos somada à falta de monitoramento dos aterros faz com que os métodos de cálculo sejam geralmente fórmulas empíricas contendo poucos parâmetros de avaliação (BORBA, 2006). Amni et al. (2013) destacam os desafios em medir as emissões em larga escala, ou seja, na situação real dos aterros, bem como as amplas flutuações das emissões no tempo e no espaço.

Cabe mencionar que em projetos de aproveitamento do biogás de aterro, as estimativas iniciais, antes da instalação dos projetos, são fundamentais para o sucesso ambiental e econômico. Estas avaliações consistem, principalmente, em levantamentos do tipo de lixo disposto, condições do aterro e do sistema de drenagem (ARCADIS Tetraplan, 2010).

Uma vez que já há existem vários projetos de MDL em aterros sanitários validados e gerando créditos de carbono, surge a questão: os aterros estão gerando os créditos previstos? A geração de créditos depende basicamente da geração de biogás e do mercado de créditos. A parte que é controlada operacionalmente é a geração de biogás.

Desta forma, o presente trabalho tem como objetivos comparar a geração de biogás prevista e captada em dois projetos de MDL em aterros sanitários de forma que serão analisados os dados dos dois maiores projetos de MDL do Brasil, localizados nos Aterros Sanitários Bandeirantes e São João, com a finalidade de comparar os parâmetros utilizados nas estimativas prévias e a captação real, e discutir potenciais razões para as diferenças.

\section{REVISÃO TEÓRICA}

A revisão teórica aborda basicamente três temas: a gestão dos resíduos sólidos e o papel dos aterros sanitários; as mudanças climáticas e como os aterros sanitários se inserem nelas; e a estimativa de emissões de gás dos aterros sanitários.

\subsection{Os aterros sanitários e a gestão de resíduos sólidos.}

Em 1995, eram gerados no Brasil 241.614 toneladas/dia de resíduos sólidos urbanos, dos quais cerca de 90.000 toneladas/dia eram de resíduos sólidos domésticos (algo em torno de 32 milhões de toneladas por ano), a maioria disposta a céu aberto (JARDIM et al.,1995).

Dados do IBGE (2010) mostram que no período da pesquisa eram gerados 259.574 toneladas/dia de resíduos urbanos, sendo que deste montante apenas 213.791 toneladas/dia eram enviados para aterros controlados, aterros sanitários, reciclagem, incineração ou compostagem. Isso mostra que houve uma evolução no tratamento dos resíduos, mas que ainda é preciso viabilizar os aterros sanitários.

Atualmente a estimativa de produção de biogás nos aterros, no mundo, alcance um total entre 20 e 60 milhões de toneladas de metano por ano. Dois terços dessas emissões são de países 
do chamado primeiro mundo, sendo que onze destes países representam $70 \%$ das emissões. Os EUA são os maiores emissores, seguidos da China, Canadá, Reino Unido e Comunidade dos Estados Independentes (USEPA, 2008).

O metano proveniente da decomposição da matéria orgânica depositada nos aterros contribui consideravelmente para as emissões globais de metano. As estimativas das emissões globais de metano, proveniente dos aterros, oscilam entre 20 e 70 t/ano, enquanto que o total das emissões globais pelas fontes antropogênicas equivale a 360 t/ano, indicando que os aterros podem produzir cerca de 6 a 20\% do total de metano (IPCC, 1995). O volume e a carga de emissão de metano num aterro são funções da quantidade total de matéria orgânica disposta, de seu conteúdo de umidade, das técnicas de compactação, da temperatura, do tipo de resíduo e do tamanho das partículas. Embora as taxas de emissão de metano decresçam após o encerramento do aterro (à medida que a fração orgânica decresce), um aterro continuará, tipicamente, a emitir metano durante muitos (20 ou mais) anos após seu encerramento (EPA, 1996).

A quantidade de resíduos sólidos urbanos coletados no Brasil em 2008 foi de 183.481,50 t/dia (equivalentes a aproximadamente $66.970 .747,50 \mathrm{t} / \mathrm{ano}$ ), sendo $18,74 \%$ superior ao registrado no ano de 2000, quando eram coletadas 149.094,30 t/dia (IBGE, 2010 e IBGE, 2002).

Apesar de vários projetos e estudos apresentarem experiências bem-sucedidas na recuperação dos resíduos sólidos, o montante reaproveitado não faz frente ao total de resíduo gerado. Há também questões de ordem técnica, ambiental, econômica e social que fazem com que a alternativa de aterramento do lixo urbano se torne predominante, frente a outras opções de destinação final de resíduos sólidos (CASSINI, 2003).

\subsection{Mecanismo de Desenvolvimento Limpo: os caminhos de um projeto}

No contexto do Protocolo de Quioto, os projetos de Mecanismo de Desenvolvimento Limpo obrigatoriamente, num primeiro momento, passam por um processo de validação, a fim de que o Projeto seja registrado na UNFCCC como geradores de créditos de carbono e, num segundo momento, ocorrem as verificações periódicas para checar e garantir a veracidade das informações fornecidas pelos Proponentes dos Projetos (PP). O terceiro momento ocorre quando a UNFCCC, por meio de seu Conselho Executivo, autoriza a emissão dos créditos de carbono (Justi e Moliterno, 2008; IIED e SSN 2009; Cordeiro et al., 2010).

Na fase de validação, o PDD (Project Design Document - Documento de Concepção do projeto, em inglês) deve conter informações detalhadas de todo os aspectos técnicos e econômicos, além de todas as características do projeto. O PDD será, então, validado por meio de uma auditoria realizada por um organismo competente, denominada Entidade Operacional Designada (EOD), credenciada pela UNFCCC. Uma vez aprovado o PDD pela EOD, ele será enviado para aprovação e registro do Conselho Executivo da UNFCCC (Justi e Moliterno, 2008; IIED e SSN, 2009).

$\mathrm{Na}$ fase de verificação ou monitoramento, o PP deve produzir relatórios para que os créditos de carbono gerados sejam emitidos. Tal verificação também é conduzida por uma EOD, que não deve ser a mesma da fase de validação a fim de evitar conflitos de interesse. Um relatório de verificação elaborado pela EOD é então enviado ao Conselho executivo da UNFCCC que, tem a função de analisar e autorizar o repasse dos CERs gerados ao Proponente do Projeto para que os 
mesmos sejam comercializados (Justi e Moliterno, 2008; IIED e SSN, 2009; Cordeiro et al., 2010) A figura 1 resume esse processo.

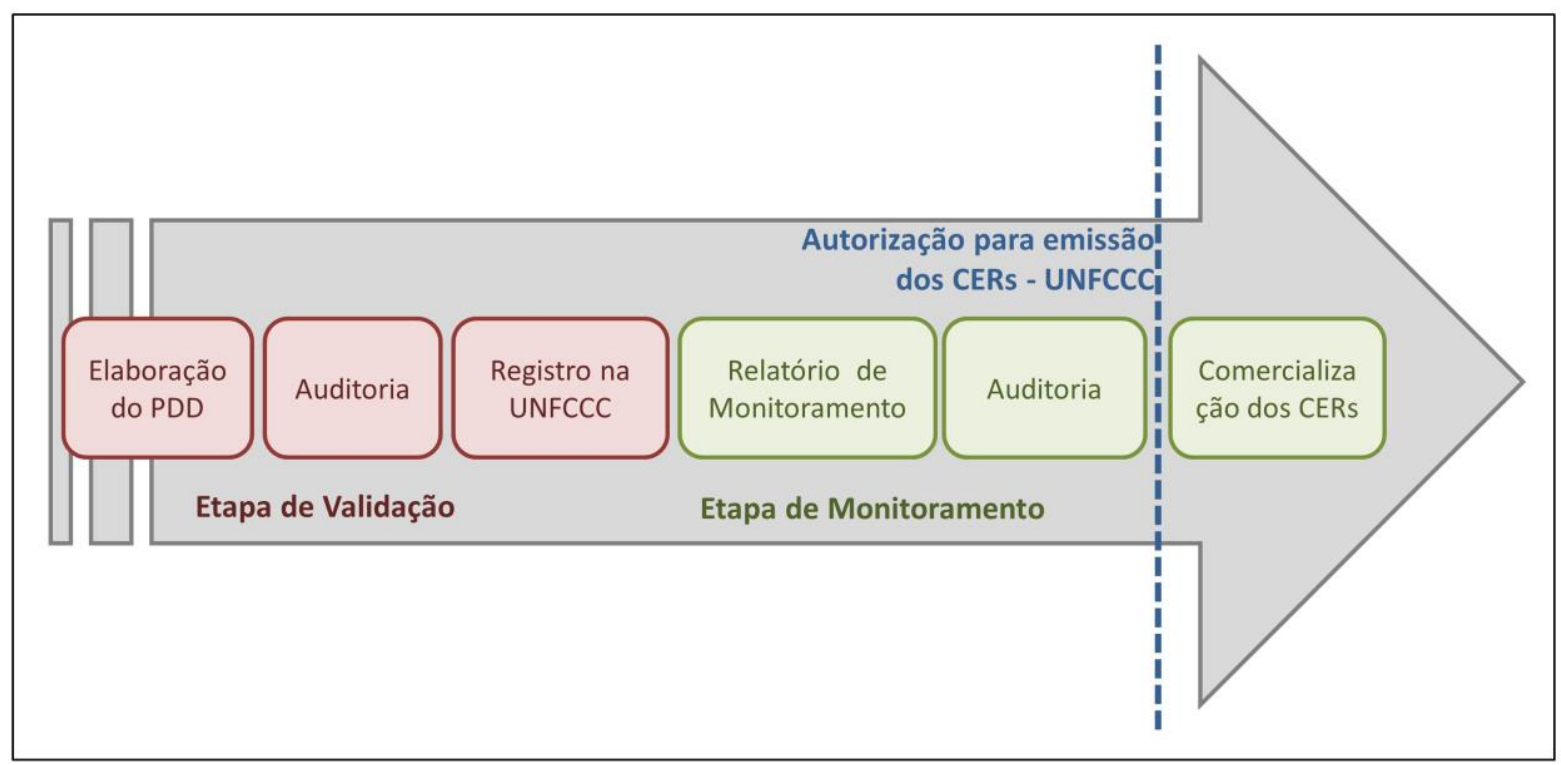

Figura 1. Principais etapas de um Projeto de MDL em Aterros Sanitários

\subsection{Aproveitamento energético do biogás de aterros}

O aproveitamento energético a partir dos Resíduos Sólidos Urbanos (RSU) é uma alternativa promissora para a geração e conservação da energia elétrica, para a redução do espaço necessário à deposição dos resíduos e como redutor de emissões de gases de efeito estufa (ARCADIS Tetraplan, 2010). " gás gerado pela decomposição da matéria orgânica presente nos RSUs é considerado uma fonte de energia renovável e, portanto, sua recuperação e seu uso energético apresentam vantagens ambientais, sociais, estratégicas e tecnológicas significativas" (ICLEI, 2010). Este gás é composto por aproximadamente $50 \%$ de metano $(\mathrm{CH} 4), 40 \%$ de dióxido de carbono (CO2), 9\% de nitrogênio, e concentrações residuais de compostos orgânicos voláteis, poluentes perigosos e outros elementos (SILVA et al., 2012). Portanto, se não operados corretamente são potenciais poluidores atmosféricos por emitirem grande quantidade de $\mathrm{CH} 4$.

A Figura 2 mostra, esquematicamente, qual o caminho desde a geração de resíduos e sua disposição em aterros até a geração de energia.

Atualmente existem dois projetos considerados de grande escala em andamento com a produção de energia pelo aproveitamento do biogás de aterros sanitários localizados no Estado de São Paulo, na Cidade de São Paulo, a saber, Usina Termelétrica Bandeirantes e Usina Termelétrica São João com capacidade instalada de $22 \mathrm{MWh}$ e $24 \mathrm{MWh}$ respectivamente. A atual capacidade instalada, descrita acima, de $46 \mathrm{MWh}$, fica muito aquém do potencial total de geração de energia por RSU projetado pelo Plano Decenal de Energia Elétrica em 2009 de 1.600 MWh para gás de lixo (EPE, 2009). 


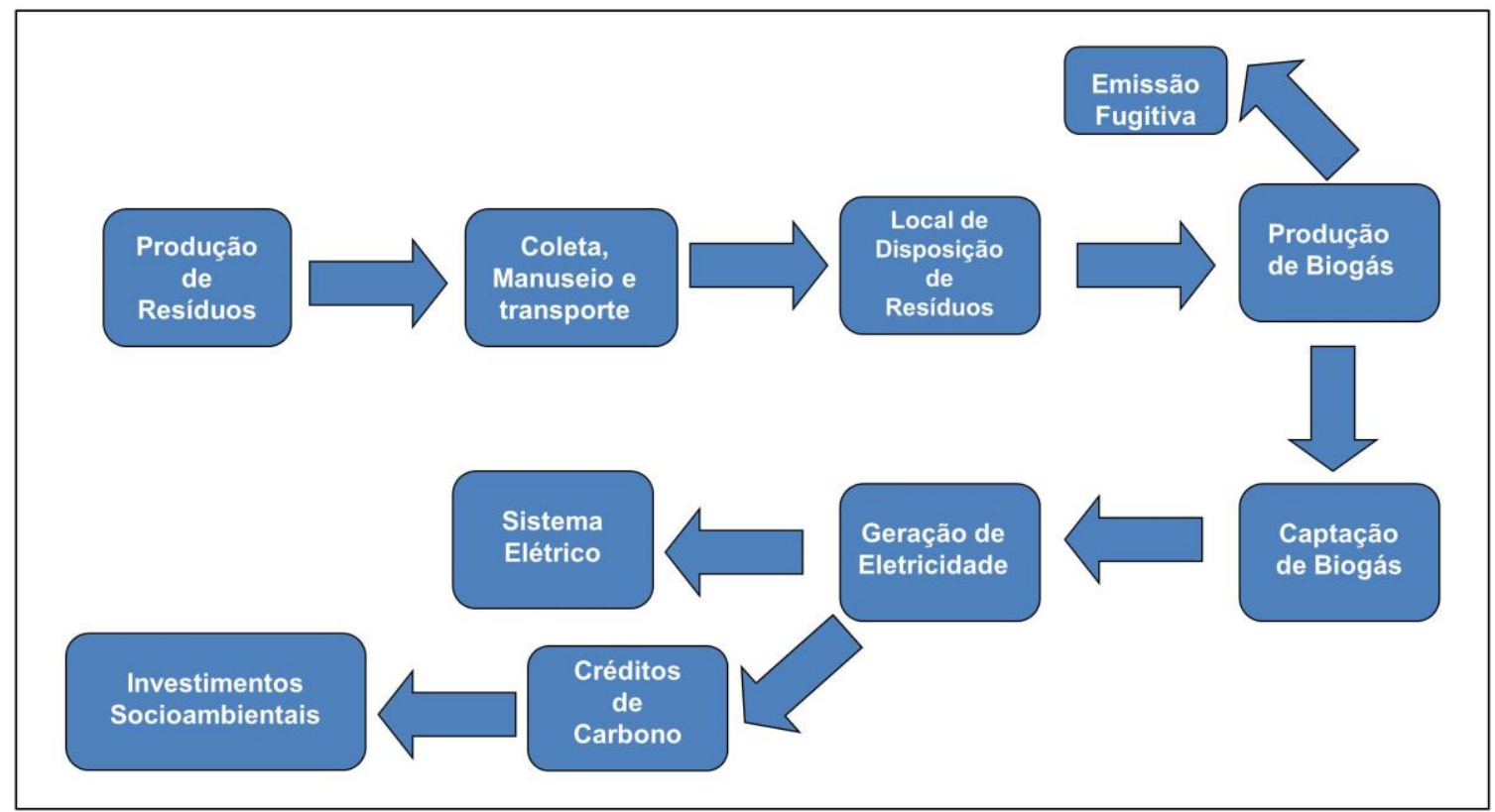

Figura 2. Fluxo esquemático da produção de resíduo pela sociedade até a geração de energia e créditos de carbono

A principal dificuldade encontrada pelos projetos de geração de energia em aterros sanitários é que, geralmente, os aterros são instalados longe dos centros urbanos, inviabilizando o projeto pelo alto custo de instalação da transmissão desta energia para subestações de distribuição de energia nos centros de carga. Por este fato, em aterros de pequeno porte, a energia gerada geralmente é consumida no próprio empreendimento ou no entorno imediato, não possibilitando ao projeto a venda da energia gerada no mercado livre de comercialização para entrega imediata, conhecido como mercado SPOT (ARCADIS Tetraplan, 2010).

A execução dos projetos de captação de biogás, com e sem geração de energia, não seria possível sem as metodologias propostas por organismos conceituados para estimar a quantidade de biogás produzido nos aterros sanitários. Elas são capazes de estimar, por exemplo, o pico da produção de biogás e por quanto tempo o Projeto será viável economicamente.

\subsection{A estimativa de emissões de gás de aterros sanitários}

Entre as diversas metodologias existentes para estimar o potencial de geração de biogás em locais de disposição de resíduos, as principais utilizadas para efetuar os cálculos são: Metodologia EPA, Metodologia IPCC, Metodologia do Banco Mundial (Modelo Scholl Canyon) e, por fim, a metodologia utilizada pela a UNFCCC, a ACM0001. 
Quadro 1. Descrição comparativa básica das principais metodologias para estimativa de emissões de gases de efeito estufa de aterros sanitários com base nas quatro principais metodologias utilizadas para estimar a produção de biogás.

\begin{tabular}{|c|c|c|c|}
\hline Metodologia & Descrição & Vantagem & Desvantagem \\
\hline IPCC & $\begin{array}{l}\text { Mais comumente utilizada para } \\
\text { a realização de inventários } \\
\text { fazendo com que sua aplicação } \\
\text { em estimativas de aterros seja } \\
\text { reduzida. }\end{array}$ & $\begin{array}{l}\text { - Maior detalhamento de dados na } \\
\text { modelagem matemática; } \\
\text { - Bem aceito por organismos } \\
\text { internacionais para cálculo dos } \\
\text { Inventários de } \\
\text { - Conservadora em relação ao tipo } \\
\text { de resíduo depositado. } \\
\text { - Cálculo para todos os tipos de } \\
\text { disposição de resíduo (altura do } \\
\text { talude) }\end{array}$ & $\begin{array}{l}\text { - Não pode ser aplicado } \\
\text { em sistemas } \\
\text { encerrados; } \\
\text { - Não considera fatores } \\
\text { climáticos; } \\
\text { - Incertezas associadas } \\
\text { aos parâmetros } \\
\text { sugeridos (50\% - 20\%) }\end{array}$ \\
\hline $\begin{array}{l}\text { Banco Mundial } \\
\text { (Modelo Scholl } \\
\text { Canyon) }\end{array}$ & $\begin{array}{l}\text { Possui o Modelo Scholl Canyon } \\
\text { para a Preparação de Gás de } \\
\text { Aterro Sanitário para Projetos } \\
\text { de Energia na América Latina e } \\
\text { Caribe (2003), que é também } \\
\text { um modelo cinético de primeira } \\
\text { ordem com base na premissa de } \\
\text { que há uma fração constante de } \\
\text { material biodegradável no } \\
\text { aterro por unidade de tempo. }\end{array}$ & $\begin{array}{l}\text { - Comumente empregado e aceito } \\
\text { no norte e sul da América; } \\
\text { - Aceita por instituições } \\
\text { financeiras interessadas em apoiar } \\
\text { projetos em aterros na América do } \\
\text { Norte, Latina e Caribe; } \\
\text { - Fácil obtenção de dados, } \\
\text { agilidade para montar banco de } \\
\text { dados. }\end{array}$ & $\begin{array}{l}\text {-Menos conservadora } \\
\text { em relação ao tipo de } \\
\text { resíduos depositados; } \\
\text { - Não fornece } \\
\text { representação } \\
\text { adequada para } \\
\text { sistemas ativos; } \\
\text { - Não inclui taxa de } \\
\text { incerteza associada aos } \\
\text { parâmetros. }\end{array}$ \\
\hline UNFCCC & $\begin{array}{l}\text { Em sua } 13 \text { a revisão, atualmente } \\
\text { é a metodologia de escolha por } \\
\text { ser a que considera a maior } \\
\text { quantidade de parâmetros para } \\
\text { realização das estimativas, } \\
\text { tornando-a a mais conservadora } \\
\text { de todas. } \\
\text { Os aterros objeto deste trabalho } \\
\text { utilizaram a versão } 02 \text { desta } \\
\text { metodologia no momento do } \\
\text { registro dos projetos junto à } \\
\text { UNFCCC. }\end{array}$ & $\begin{array}{l}\text { - Banco de dados mais completo } \\
\text { devido a complexidade dos dados } \\
\text { necessários; } \\
\text { - Fator de incerteza associada aos } \\
\text { parâmetros incluso na modelagem } \\
\text { matemática; } \\
\text { - Utilização de dados } \\
\text { climatológicos como variável do } \\
\text { modelo; } \\
\text { - Maior conservadorismo quanto } \\
\text { aos tipos resíduos depositados; } \\
\text { - Aprovada e consolidada para o } \\
\text { cálculo da linha de base de projetos } \\
\text { em aterros no âmbito do MDL } \\
\text { - Pode ser aplicada em todos os } \\
\text { tipos de sistema. }\end{array}$ & $\begin{array}{l}\text { - Possível ausência de } \\
\text { informações } \\
\text { adequadas quanto aos } \\
\text { tipos de resíduos } \\
\text { depositados nos } \\
\text { municípios r } \\
\text { questionados devido à } \\
\text { complexidade de } \\
\text { dados. }\end{array}$ \\
\hline
\end{tabular}

Fonte - Adaptado de ARCADIS Tetraplan, 2010.

No presente estudo, para fins de cálculo de estimativa de biogás, foram utilizadas duas versões da Metodologia UNFCCC ACM0001, sendo as versões 02 e 13. A versão 02 foi utilizada para estimar o potencial de produção de biogás de ambos os aterros objeto de estudo deste trabalho no momento da elaboração dos PDDs, além de ser a versão mais atualizada no momento das estimativas. A versão 13 foi selecionada por ser a versão mais recente da metodologia ACM0001 no momento da realização dos cálculos. Ambas as versões foram comparadas com a real captação de biogás nos Aterros Bandeirantes e São João. 
O Quadro 2 mostra as fórmulas das duas versões da metodologia ACM0001 aplicadas na estimativa do potencial de geração de biogás dos Aterros Bandeirantes e São João.

Quadro 2. Fórmulas e parâmetros das versões 2 e 13 da Metodologia UNFCCC ACM0001

\begin{tabular}{|c|c|}
\hline Metodologia & Fórmula \\
\hline & $E R_{y}=\left(M D_{\text {project }, y}-M D_{\text {reg, } y}\right) * G W P_{C H 4}+E G_{y} \cdot C E F_{\text {electricity }, y}+E T_{y} * C E F_{\text {thermal }, y}$ \\
\hline $\begin{array}{c}\text { ACM0001 - ver. } \\
02\end{array}$ & $\begin{array}{l}\text { ER y = Redução de Emissões } \\
\text { MD Project ,y = Quantidade de metano realmente destruída / queimada durante o ano y } \\
\text { (tCH4) } \\
\text { MD reg, y = Quantidade de metano que deveria ter sido destruída / queimada durante o ano } \\
\text { y na ausência da atividade de projeto ( } \mathrm{tCH} 4) \text {; } \\
\text { GWP CH4 = Potencial de Aquecimento Global (GWP) do metano } \\
\text { EG y = Quantidade líquida de eletricidade deslocada durante o ano y (MWh) } \\
\text { CEF electricity, y = A intensidade das emissões de CO2 da energia deslocada (tCO2e/TJ) } \\
\text { ET y = Quantidade de energia térmica deslocada durante o ano y (TJ) } \\
\text { CEF thermal, y = A intensidade das emissões de CO2 da energia térmica deslocada (tCO2e/TJ) }\end{array}$ \\
\hline \multirow[b]{2}{*}{$\begin{array}{c}\text { ACM0001 - ver. } \\
13\end{array}$} & $\mathrm{BE}_{\mathrm{CH} 4 \mathrm{SWDS}, \mathrm{y}}=\varphi \cdot(1-\mathrm{f}) \cdot \mathrm{GWP}_{\mathrm{CH} 4} \cdot(1-\mathrm{OX}) \cdot \frac{16}{12} \cdot \mathrm{F} \cdot \mathrm{DOC}_{\mathrm{f}} \cdot \mathrm{MCF} \cdot \sum_{\mathrm{x}=1}^{y} \sum_{\mathrm{j}} \mathrm{W}_{\mathrm{j}, \mathrm{x}} \cdot \mathrm{DOC}_{\mathrm{j}} \cdot \mathrm{e}^{-\mathrm{k}_{\mathrm{j}}(\mathrm{y}-\mathrm{x})} \cdot\left(1-\mathrm{e}^{-\mathrm{k}_{\mathrm{j}}}\right)$ \\
\hline & $\begin{array}{l}\phi=\text { fator de correção do modelo de incertezas }(0,9) \\
f=\text { fração de metano do aterro capturado, queimado, utilizado como combustível ou de outra } \\
\text { maneira } \\
\text { GWPCH4 = Potencial de Aquecimento Global (GWP) do metano } \\
\text { OX = fator de oxidação (refletindo a quantidade de metano do aterro que é oxidado no solo } \\
\text { ou em outros materiais que cobrem os resíduos) } \\
F=\text { fração de metano no biogás (em volume) }(0,5) \\
\text { DOCf = fração de carbono orgânico degradável (DOC) } \\
\text { MCF = fator de correção de metano } \\
\text { WJ, } x=\text { quantidade por tipo de resíduos orgânicos j dispostos no aterro no ano x (t) } \\
\text { DOCj = fração de carbono orgânico degradável (em peso), por tipo de resíduos j } \\
\text { kj = taxa de decaimento para o tipo de resíduos } j \\
j=\text { tipo de resíduos (índice) } \\
x=\text { ano durante o período de crédito: } x \text { executado a partir do primeiro ano do primeiro período } \\
\text { de créditos ( } x=1 \text { ) para o ano y para o qual são calculadas as emissões evitadas ( } x=y \text { ) } \\
\text { y = ano para o qual são calculadas as emissões de metano }\end{array}$ \\
\hline
\end{tabular}

Fonte - UNFCCC (2012).

\section{MÉTODOS E TÉCNICAS}

A pesquisa é um estudo de casos múltiplos (YIN, 2001), de natureza descritiva e exploratória. Descritiva porque trata-se de obter dados dos resultados dos casos, e exploratória porque ao estudar as potenciais causas não se aprofunda no tema, mas sim são discutidas possibilidades. A fundamentação teórica foi construída tendo como base uma revisão bibliográfica e a consulta a quatro metodologias distintas de estimativa de captação de biogás em aterros sanitários, as quais tiveram suas variáveis analisadas para verificação dos distintos parâmetros solicitados no momento do cálculo de estimativa de biogás.

Para a estimativa de biogás nos dois projetos de MDL em questão, Bandeirantes e São João, foram utilizadas as versões 2 e 13 da metodologia UNFCCC ACM0001. A versão 02 foi utilizada para estimar o potencial de produção de biogás de ambos os aterros momento da elaboração dos PDDs, além de ser a versão mais atualizada na época. A versão 13 foi selecionada por ser a versão mais 
atual da metodologia ACM0001 no momento da realização dos cálculos. Após a análise dos parâmetros, foi verificada a possibilidade de aplicação nos dados fornecidos pelos Projetos Bandeirantes e São João, bem como a estimativa de captação de biogás em cada uma das metodologias.

Os dados de geração de gás prevista para cada uma das versões da metodologia ACM001 e dados de geração de gás foram testados estatisticamente, testando-se as seguintes hipóteses:

a) Hipótese Ho: a geração de biogás prevista pela metodologia ACM 001 não se relaciona com as quantidades verificadas de geração real de biogás.

Para verificar esta hipótese, foi usado o teste do coeficiente de correlação de Pearson (MARTINS; TEOPHILO, 2009; COSTA NETO, 1988);

b) Hipótese Ho: as quantidades de biogás efetivamente geradas são diferentes das quantidades previstas pela metodologia ACM001 em suas versões 2 e 13.

Para verificar esta hipótese, foi verificado teste ANOVA de diferenças de médias seguido do teste de Tukey dos intervalos de confiança para identificação das médias diferentes, quando existentes (MARTINS; TEOPHILO, 2009; COSTA NETO, 1988).

Os dados foram processados com uso do software Minitab 16, que calcula para os testes de correlação e ANOVA o parâmetro $p$-value, que deve ser menor que 0,05 para que as hipóteses Ho sejam rejeitadas.

Grande parte das informações necessárias para realizar os cálculos foi fornecida pelos Projetos e podem ser confirmadas nas respectivas páginas dos Projetos no site da UNFCCC (www.unfccc.int), com o número de registro dos Projetos - 0164 e 0373, para Bandeirantes e São João, respectivamente.

Finalizando o estudo, são discutidas possíveis causas adicionais das diferenças entre a produção real de biogás e a produção verificada, utilizando-se o método de Ishikawa (1993). Algumas das variáveis analisadas são: pluviometria, temperatura, gravimetria dos resíduos e porcentagem de metano presente no biogás.

\section{O CONTEXTO DOS ATERROS ESTUDADOS}

\subsection{Aterro Sanitário Bandeirantes}

O Projeto Bandeirantes de Geração de Energia foi desenvolvido para captar o biogás produzido no Aterro Sanitário Bandeirantes e gerar energia. O aterro começou a operar em 1978 e foi encerrado em 2007 e recebeu durante sua vida útil aproximadamente 35 milhões de toneladas de resíduos das Zonas Norte e Oeste do Município de São Paulo (sendo nos últimos anos, aproximadamente 7,5 mil toneladas/dia). O projeto, no momento de sua concepção, pretendia deixar de emitir algo em torno de 6 milhões de toneladas de CO2 para a atmosfera e gerar $20 \mathrm{MWh}$ de energia, suficientes para abastecer 100 mil residências (JUSTI e MOLITERNO, 2008).

Por se tratar de um aterro municipal, no momento da concessão para a exploração do biogás, a Biogás Energia Ambiental S.A venceu as concorrentes por repassar $50 \%$ dos créditos de carbono gerados no projeto para a prefeitura Municipal de São Paulo (PMSP). Desta forma, a PMSP, por meio da Secretaria Municipal do Verde e Meio Ambiente (SVMA), se responsabilizou 
por investir o dinheiro arrecadado com a venda dos CERs em projetos socioambientais no entorno do Aterro, a fim de minimizar os impactos causados à comunidade nos 29 anos de operação do aterro (JUNQUEIRA, 2005).

\subsection{Aterro Sanitário Sítio São João}

O Projeto São João de Geração de Energia foi desenvolvido para captar o biogás produzido no Aterro Sanitário Sítio São João e gerar energia. O aterro teve sua operação iniciada no ano de 1992 e foi encerrado em março de 2009. Recebeu durante sua vida útil aproximadamente 25 milhões de toneladas de resíduos das Zonas Sul e Leste do Município de São Paulo e, assim como o Aterro Bandeirantes, nos últimos anos de sua operação chegou a receber aproximadamente 7,5 mil toneladas/dia de resíduos, das 15 mil geradas diariamente no município.

A divisão dos CERs gerados pelo Projeto ocorreu nos mesmos moldes do Projeto Bandeirantes, na proporção de $50 \%$ para cada o empreendedor e $50 \%$ para a PMSP. A comercialização também seguiu o mesmo modelo (JUNQUEIRA, 2005).

Em ambos os casos, a viabilidade econômica depende tanto da venda de créditos de carbono quanto da venda da energia elétrica gerada. Os contratos de fornecimento de energia para a distribuidora preveem pesadas multas em caso de não entrega da energia, no sistema takeor-pay."

\section{RESULTADOS}

A seguir são apresentados os resultados calculados pela Metodologia UNFCCC ACM0001, nas versões 02 e 13 respectivamente, para os Projetos Bandeirantes e São João e, também, o real captado e já certificado pela UNFCCC como créditos de carbono.

Tabela 1. Estimativas de produção de biogás e a captação real nos aterros Bandeirantes e São João

\begin{tabular}{|c|c|c|c|c|c|c|}
\hline \multirow[b]{2}{*}{ Ano } & \multicolumn{3}{|c|}{ Bandeirantes } & \multicolumn{3}{|c|}{ São João } \\
\hline & $\begin{array}{l}\text { Estimativa de } \\
\text { Emissões } \\
\left(\mathrm{t} \mathrm{CO}_{2}\right) \\
\text { calculada pela } \\
\text { metodologia } \\
\text { ACM0001- rev } \\
02(1)\end{array}$ & $\begin{array}{l}\text { Estimativa de } \\
\text { Emissões } \\
\left(\mathrm{t} \mathrm{CO}_{2}\right) \\
\text { calculada pela } \\
\text { metodologia } \\
\text { ACM0001- } \\
\text { rev13 (2) }\end{array}$ & $\begin{array}{l}\text { Emissões } \\
\text { verificadas } \\
\left.(\mathrm{t} \mathrm{CO})_{2}\right) \\
(1)\end{array}$ & $\begin{array}{c}\text { Estimativa de } \\
\text { Emissões } \\
(\mathrm{t} \mathrm{CO} 2) \\
\text { calculada pela } \\
\text { metodologia } \\
\text { ACM0001-rev02 } \\
(3)\end{array}$ & $\begin{array}{c}\text { Estimativa de } \\
\text { Emissões } \\
(\mathrm{t} \mathrm{CO} 2) \\
\text { calculada pela } \\
\text { metodologia } \\
\text { ACM0001-rev13 } \\
(2)\end{array}$ & $\begin{array}{l}\text { Emissões } \\
\text { Verificadas } \\
\left(\mathrm{t} \mathrm{CO}_{2}\right) \text { (3) }\end{array}$ \\
\hline 2004 & 748.624 & 1.035 .510 & 506.063 & - & - & - \\
\hline 2005 & 1.086 .919 & 995.370 & 552.069 & - & - & - \\
\hline 2006 & 1.364 .960 & 1.015 .351 & 612.173 & 686.170 & 250.688 & - \\
\hline 2007 & 1.236 .153 & 851.128 & 726.764 & 1.070 .233 & 391.003 & 368.367 \\
\hline 2008 & 1.120 .186 & 672.813 & 586.770 & 968.442 & 353.815 & 590.333 \\
\hline 2009 & 1.015 .780 & 533.332 & 375.248 & 876.797 & 320.333 & 452.109 \\
\hline 2010 & 921.782 & 433.793 & 304.232 & 794.288 & 361.779 & 483.128 \\
\hline 2011 & 768.201 & 361.517 & $N / D$ & 720.002 & 405.320 & 301.398 \\
\hline 2012 & 654.396 & 307.960 & $N / D$ & 653.121 & 445.787 & 87.026 \\
\hline
\end{tabular}

Fontes - (1) UNFCCC: PDD Projeto Bandeirantes - Disponível em http://cdm.unfccc.int/Projects/DB/DNVCUK1134130255.56. (2) Estimativas elaboradas pelos autores. (3) UNFCCC: Projeto Bandeirantes - Disponível em: (3) UNFCCC: PDD Projeto São João - Disponível em: http://cdm.unfccc.int/Projects/DB/DNV-CUK1145141778.29. 
A diferença de estimativas no caso do Aterro Bandeirantes é de 30,4\% considerando-se o total no período 2004 a 2012, e as emissões verificadas são 51,2\% menores que as previstas no PDD no período com dados de validação (2004-2010).

No caso do aterro São João, a diferença de estimativa é mais dramática, sendo a estimativa pela ACM0001 ver 13 menor em 56,2\% que a estimativa original. No entanto, no período verificado (2007 a 2012), a diferença entre a previsão da ver 13 para a quantidade verificada é de apenas $0,1 \%$, no total, embora a produção de biogás tenha sido maior que o previsto no início e menor que o previsto nos anos mais recentes. De qualquer modo, a produção de biogás verificada foi $55,1 \%$ menor que o originalmente previsto

Os resultados foram submetidos aos testes estatísticos, conforme descrito na seção 3. 0 Quadro 3 mostra os resultados.

Quadro 3. Resumo dos testes estatísticos realizados.

\begin{tabular}{|c|c|c|}
\hline & Aterro Bandeirantes & Aterro Sítio São João \\
\hline $\begin{array}{l}\text { Correlação de Pearson } \\
\text { ACM001 rev2 x } \\
\text { emissões verificadas }\end{array}$ & $\begin{array}{l}r=0,628 \\
p=0,131\end{array}$ & $\begin{array}{l}r=0,634 \\
p=0,176\end{array}$ \\
\hline $\begin{array}{l}\text { Correlação de Pearson } \\
\text { ACM001 rev13 x } \\
\text { emissões verificadas }\end{array}$ & $\begin{array}{l}r=0,671 \\
p=0,099\end{array}$ & $\begin{array}{l}r=-0,862 \\
p=0,027\end{array}$ \\
\hline ANOVA unidirecional & $P=0,003$ & $P=0,000$ \\
\hline com Teste Tukey & $\begin{array}{l}\text { Agrupamento A: ACM001 ver } 2 \\
\begin{array}{r}\text { Agrupamento B: ACM001 ver } 13 \\
\text { Emissões verificadas } \\
P=0,003\end{array}\end{array}$ & $\begin{array}{l}\text { Agrupamento A: ACM001 ver } 2 \\
\begin{array}{r}\text { Agrupamento B: ACM001 ver } 13 \\
\text { Emissões verificadas }\end{array} \\
P<0,001\end{array}$ \\
\hline
\end{tabular}

No caso do Aterro Bandeirantes, os resultados estatísticos mostram que, ao nível de significância de $5 \%$ não há evidência estatística de correlação entre a geração real e qualquer das duas metodologias usadas para a previsão da geração. Por outro lado, o teste ANOVA seguido de Tukey permite concluir que os resultados da metodologia ACM001 ver 13 se aproximam mais dos resultados reais que a metodologia $A C M 001$ ver 2 , o que poderia ser considerado indício de alguma melhoria na previsão.

No caso do aterro São João, a geração de biogás prevista pela metodologia ACM 001 ver 2 não apresentou correlação estatística com a geração de biogás verificada, ao nível de significância de 5\%. Por outro lado, os resultados da metodologia ACM 001 ver 13 apresentaram uma correlação negativa estatisticamente significante. A correlação negativa se explica porque a metodologia previu uma produção de biogás crescente entre 2009 e 2012, no entanto houve um forte decréscimo entre 2010 e 2012. Por outro lado, na média do período houve uma boa aproximação da previsão, e o teste Tukey mostrou que os resultados da metodologia ACM 001 ver 13 se aproximam mais do real, na média, do que a metodologia em sua revisão 2.

\section{DISCUSSÃO}

A primeira conclusão é que, na média dos resultados anuais, houve um importante aumento no poder de previsão da metodologia ACM0001 na versão 13 quando comparada a 
versão 2, conforme demonstraram os testes ANOVA e Tukey. Isso é uma boa notícia para projetos novos, que poderão ter sua viabilidade econômica mais bem avaliada quando da concepção do projeto. Para projetos antigos, fica a má notícia de que foram realmente concebidos com uma metodologia de cálculo imprecisa.

Por outro lado, a previsão ano a ano continua pobre, conforme demonstra a falta de correlação ou correlação negativa entre os resultados verificados e previstos, o que tem a consequência adicional de tornar o fluxo de caixa ainda menos previsível que a média de desempenho.

Ambos os casos representam grandes perdas financeiras por não gerar os créditos previstos para venda, e por não gerar a energia contratada para venda.

\subsection{Consequências da discrepância entre resultados previstos e reais}

As principais consequências das discrepâncias entre as estimativas de produção de biogás e o real captado podem ser listadas como: perdas financeiras em decorrência da não geração de créditos de carbono previsto e também da geração de energia, considerando que a venda de energia é realizada por meio de contrato entre compradores e geradores e o não fornecimento acarreta em multas pesadas.

No caso da revalidação do projeto junto à UNFCCC, as estimativas serão obrigatoriamente mais conservadoras, tendo em vista a evolução da metodologia no que tange a captação de biogás, geração de créditos de carbono e geração de energia.

Atualmente, as avaliações em relação à eficiência de estanque para gases de cobertura final em aterro são praticamente inexistentes, pois no lugar de tal eficiência de estanque costuma-se adotar valores padrões de eficiência do sistema modelado utilizado - entre 60 a $80 \%$ de eficiência (SILVA, FREITAS e CANDIANI, 2012).

Para a Prefeitura do Município de São Paulo, que recebe $50 \%$ dos créditos gerados em ambos os projetos, a principal consequência é a redução da verba a ser disponibilizada para a implantação de projetos socioambientais na região dos aterros. No entanto, Justi e Moliterno (2008) constataram uma dificuldade por parte do órgão público em estabelecer os projetos para a aplicação dos recursos oriundos dos leilões dos créditos de carbono.

\subsection{Causas potenciais da discrepância entre geração real e prevista}

A fim de discutir as potenciais causas, utilizamos o diagrama tipo espinha-de-peixe, do tipo proposto por Ishikawa (1993), conforme mostra a figura 3. Nossa análise não pretendeu ser exaustiva, mas apontar possíveis caminhos para os estudos futuros no sentido de aprimorar as estimativas de geração, ou os métodos de operação dos aterros que favoreçam a máxima geração de biogás para aproveitamento energético.

Algumas dessas falhas são menos prováveis, como, por exemplo, aquelas associadas a equipamentos e instrumentos de medição, porque o processo de medição e de extração do gás são foco importante durante as auditorias, sendo exigidos certificados de calibração e aferição de todos os equipamentos e instrumentos. 
No entanto, a composição gravimétrica do resíduo depositado é algo que pode variar bastante e normalmente não é acompanhada tão de perto ao longo da operação dos locais de disposição, para saber se está de acordo com o planejado. Para a estimativa da geração de biogás é fundamental saber a quantidade de matéria orgânica presente no total de resíduo depositado e essa quantidade normalmente também é estimada ou verificada em análises gravimétricas dos resíduos (SILVA, FREITAS e CANDIANI, 2012). Este fator interfere diretamente na quantidade de $\mathrm{CH} 4$ presente no biogás, normalmente em torno de $50 \%$, portanto pode ser uma das causas da baixa geração de biogás (TCHOBANOGLOUS, THEISEN e VINIL, 1993).

É importante ressaltar que outros projetos no Brasil apresentam problemas similares: Outros autores relataram problemas parecidos em outros aterros, como Brito Filho (2005), que relata que para ensaios realizados nos gases provenientes do aterro sanitário de Nova Iguaçu, localizado na região metropolitana do Rio de Janeiro, os valores de metano variaram entre $44 \mathrm{e}$ $76 \%$ e os valores de dióxido de carbono variaram entre 8 e 15\%. No aterro controlado "Terra Brava", também localizado na região metropolitana do Rio de Janeiro, o autor relata quantidades de metano variando entre 40 e $76 \%$, para valores de dióxido de carbono variando entre 7 e $15 \%$.

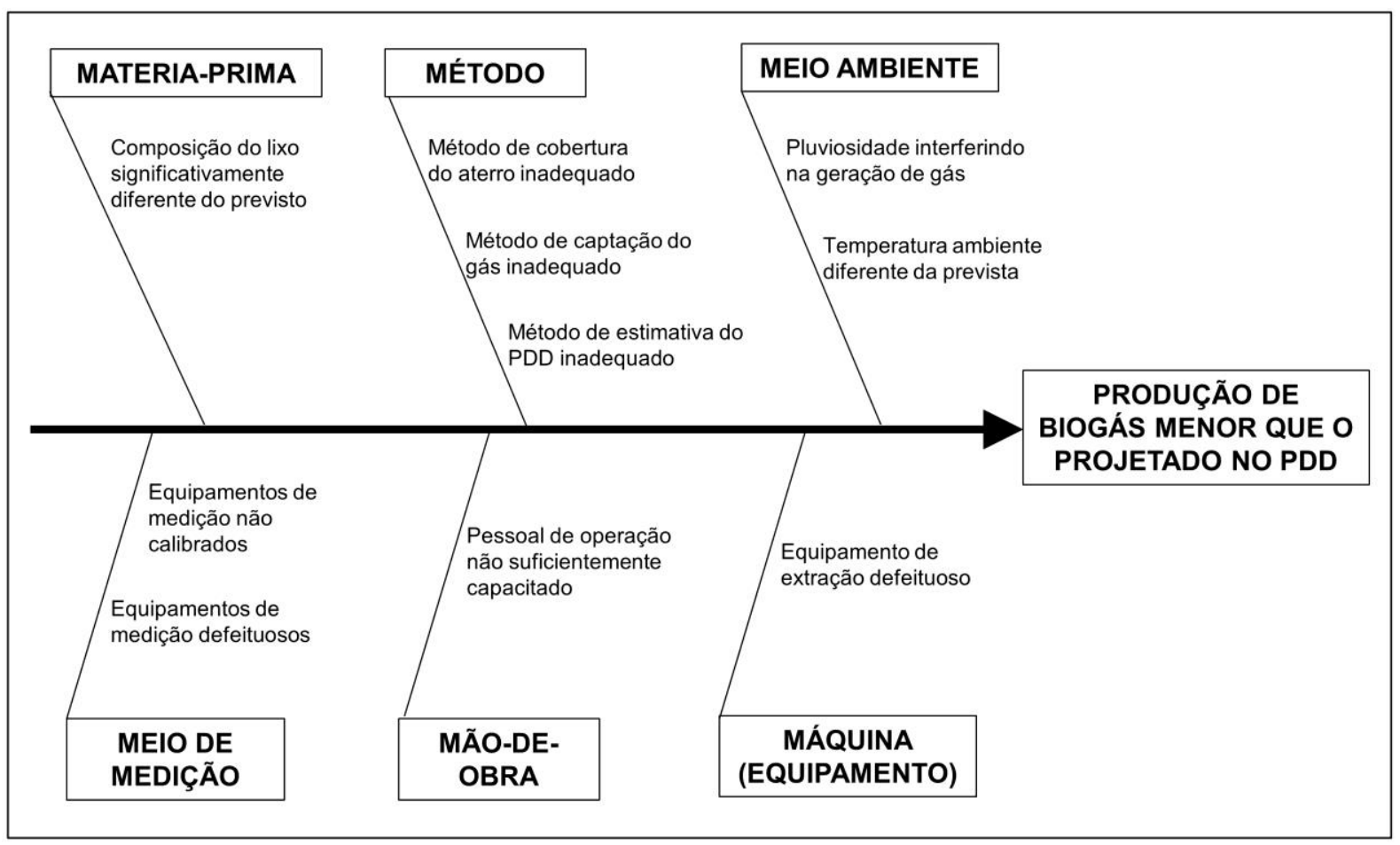

Figura 3 - Potenciais causas da produção de biogás menor que o projetado no PDD.

Real (2005), ao estudar os gases presentes no Lixão de Paracambí, localizado no Município de Paracambí, Estado do Rio de Janeiro, apresenta quantidades de metano variando entre 64 e $72 \%$ e valores de dióxido de carbono inferiores a $10 \%$.

Souza et al. (2011) afirmam que o Aterro Sanitário de Palmas possui potencial de geração de biogás que pode ser utilizado para produzir energia elétrica. No entanto observou-se também, que as condições para o aproveitamento deste potencial estão comprometidas, já que o aterro não dispõe de estrutura adequada para a captação e tratamento dos gases. 
A cobertura final dos taludes e platô dos aterros é outra questão que deve ser observada com cautela, pois trincas e rachaduras podem fazer com que ocorra emissão fugitiva do biogás presente no maciço do aterro para a atmosfera. Sendo assim, uma cobertura argilosa é recomendada. No Aterro Bandeirantes foi colocada no platô uma manta de Polietileno de Alta Densidade (PEAD) após verificação de vazamento de biogás, fato que prejudicava a geração de créditos de carbono e energia. Conforme Silva, Freitas e Candiani (2012), é importante observar que o valor fixado nas modelagens considera não só a possível perda de gás pela superfície, mas também as condições ideais de compactação, cobertura, temperatura e umidade para a biodegradação dos resíduos orgânicos presentes no maciço sanitário do aterro que podem interferir na produção de gás.

Da mesma forma, o modelo matemático de estimativa de produção de biogás não leva em consideração os fatores ambientais como a quantidade e vazão das chuvas e variação de temperatura, que são diferentes nos países onde as metodologias foram criadas e primeiramente aplicadas.

O modo de operação do aterro também pode influenciar negativamente a produção de biogás, uma vez que grande parte dos aterros em operação não foi estruturada para receber, mesmo seguindo as normas de engenharia estabelecidas na NBR 8.469 (ABNT, 1992).

\section{CONSIDERAÇÕES FINAIS}

Observa-se que a metodologia o uso da metodologia ACM 001 não tem tido sucesso em apresentar uma previsão de geração de biogás, nos projetos estudados, que se aproxime da realidade. As diferenças entre as quantidades previstas e verificadas são relevantes do ponto de vista dos valores envolvidos e de expectativas de recebimento de créditos e de lucros, gerando a necessidade de compra de créditos para compensar os créditos não gerados na operação.

A viabilização de novos projetos de reaproveitamento energético de gás de aterro vai depender de aperfeiçoamento nos métodos de estimativa e do estudo de métodos de operação que favoreçam a geração e aproveitamento de gás.

Futuras pesquisas poderiam abordar:

a) aprofundamento da análise de causas, que provavelmente vai demandar dados operacionais. A pergunta que fica é: teremos dados operacionais para fazer a análise das causas? Pode ser que tais dados não sejam coletados rotineiramente na operação dos aterros, ou não com a qualidade necessária, particularmente condições de operação da cobertura, composição dos resíduos, pluviosidade, entre outras.

b) ajustes dos modelos a realidade brasileira: algumas suposições sobre as condições ambientais e de operação dos aterros podem ser diferentes dos pressupostos originais. Seria preciso explorar mais tais suposições e corrigi-las;

c) avaliar os riscos financeiros e a gestão dos aspectos contratuais de comercialização de créditos de carbono e energia, no caso de discrepâncias. 


\section{REFERÊNCIAS}

1. ABNT - Associação Brasileira de Normas Técnicas. 1992. Projetos de aterros sanitários de resíduos sólidos urbanos. NBR 8.419 .

2. ARCADIS Tetraplan. 2010. Estudo sobre o Potencial de Geração de Energia a partir de Resíduos de Saneamento (lixo, esgoto), visando incrementar o uso de biogás como fonte alternativa de energia renovável. Disponível em: <http://www.mma.gov.br/estruturas/164/_publicacao/164_publicacao10012011033201.pdf $>$. Acesso em 15 jun.2012.

3. BORBA, S. M. P. 2006. Análise de Modelos de Geração de Gases em Aterros Sanitários: Estudo de Caso. Dissertação. Mestrado em Engenharia Civil. Rio de Janeiro. 134 p. UFRJ - Universidade Federal do Rio de Janeiro.

4. BRASIL, 2005. DECRETO № 5.445, DE 12 DE MAIO DE 2005. Disponível em: http://www.planalto.gov.br/ccivil_03/_Ato2004-2006/2005/Decreto/D5445.htm. Acesso em 20 set,2013.

5. ___ 2010. Política Nacional de Resíduos Sólidos. Lei no 12.305, de 2 de agosto de 2010.

6. BRITO FILHO, L. F. 2005. Estudo de Gases em Aterros. Casos: Nova Iguaçu e Terra Brava. Dissertação. Mestrado, Programa de Engenharia Civil /COPPE /UFRJ, Rio de Janeiro.

7. CASSINI, S. T. (coord). 2003. Digestão de Resíduos Sólidos Orgânicos e Aproveitamento do Biogás. Vitória: ABES. Disponível em <http://www.finep.gov.br/prosab/livros/ProsabStulio.pdf $\geq$ Acesso em 22 ago.2012.

8. COSTA NETO, P. L. O. Estatística. São Paulo: Edgard Blucher, 1988.

9. EPE, Empresa de Pesquisa Energética. 2009. Plano Decenal de Expansão de Energia: Relatório Final - 2008 a 2017 (Volume I). Brasília. Disponível em: <http://www.epe.gov.br/pdee/forms/epeestudo.aspx>. Acesso em 28 jul.2012.

10. ICLEI, Governos Locais para a Sustentabilidade. 2010. Manual para aproveitamento do biogás: volume dois, efluentes urbanos. São Paulo. Disponível em: <http://www.iclei.org.br/residuos/site/?page_id=668>. Acesso em 21 jun.2012.

11. IBGE, Instituto Brasileiro de Geografia e Estatística. 2002. Pesquisa Nacional de Saneamento Básico 2000. Rio de Janeiro: IBGE. Disponível em: <http://www.ibge.gov.br/home/estatistica/populacao/condicaodevida/pnsb/default.shtm>. Acesso em 22 jun.2012.

12. Instituto Brasileiro de Geografia

e Estatística. 2010. Pesquisa Nacional de Saneamento Básico 2008. Disponível em: <http://www.ibge.gov.br/home/estatistica/populacao/condicaodevida/pnsb2008/PNSB_200 8.pdf $\geq$. Acesso em 9 jun.2012.

13. IPCC, Intergovernmental Panel on Climate Change. 1995. The Science of Climate Change Summary for Policymakers. Office Graphics Studio. Madrid.

14. ISHIKAWA, K. 1993. Controle de qualidade total: à maneira japonesa. Rio de Janeiro: Campus.

15. JARDIM N.S. (coord.). 1995. Lixo municipal: manual de gerenciamento integrado. São Paulo: IPT/CEMPRE. 
16. JUNQUEIRA, M. S. D. 2006. Project Design Document - Bandeirantes Landfill Gas to Energy Project (BLFGE).

Disponível

em: https://cdm.unfccc.int/filestorage/B/W/X/BWXKQVUY9Z67EATMROFC8JDG5IS413/BLFGE_P DD_v03_03012012_submission.pdf?t=d0N8bXJseWVrfDCRnNSQfrUL5clgQL3dY3fV Acessado em: 09 de agosto de 2012.

17. JUNQUEIRA, M. S. D. 2004. Project Design Document - São João Landfill Gas to Energy Project (BLFGE). Disponível

em: <http://cdm.unfccc.int/filestorage/8/O/0/8001DQS97FACYKBE6LWNUGVX52ZPM/PDD.PDF ?t=bOF8bXJseWplfDATAVB-vZOPwBzK-Oc-7UVa $\geq$. Acessado em: 09 ago.2012.

18. JUSTI, J. G.; MOLITERNO, M. 2008. Geração de energia elétrica por meio de biogás extraído do Aterro Sanitário Bandeirantes e o Mecanismo de Desenvolvimento Limpo como indutor de investimentos socioambientais. São Paulo. 90p. Monografia - Especialização em Gestão Ambiental e Negócios no Setor Energético. Universidade de São Paulo - USP.

19. MARTINS, G. A.; TEOPHILO, C. R. Metodologia da Investigação Científica para Ciências Sociais Aplicadas. São Paulo: Atlas, 2009.

20. MCT, Ministério da Ciência e Tecnologia. 2010. Status atual das atividades de projeto no âmbito do Mecanismo de Desenvolvimento Limpo (MDL) no Brasil e no mundo. Disponível em:<http://www.mct.gov.br/upd_blob/0019/19545.pdf >. Acesso em 17 jul.2012.

21. REAL, J. L. G. 2005. Riscos Ambientais em Aterros de Resíduos Sólidos com Ênfase na Emissão de Gases. (Dissertação de Mestrado). Programa de Engenharia Civil/COPPE/UFRJ, Rio de Janeiro.

22. SILVA, T. N; FREITAS, F. S. N.; CANDIANI, G. 2013. Emissões Superficiais de Gás de Aterros Sanitários de Grande Porte com Projeto de Mecanismo de Desenvolvimento Limpo - MDL. Revista de Engenharia Sanitária e Ambiental 18(2):95-104.

23. SOUZA, R. M; SERRA, J. C.V; JUNIOR, J. C. Z; SANTOS, D. R. R. 2011. Análise do Potencial Energético do Biogás Proveniente do Aterro Sanitário de Palmas/TO para Geração de Energia Elétrica. Revista AJES. Disponível em: $\leq$ http://www.revista.ajes.edu.br/arquivos/artigo_20110907160448.pdf>. Acesso em 06 jul.2012.

24. TCHOBANOGLOUS, G.; THEISEN, H.; VINIL, S. 1993. Integrated solid waste management: engineering principles and management issues. USA: McGraw-Hill.

25. UNEP, United Nation Environment Program. 2011, Towards a Green Economy: Pathways to Sustainable Development and Poverty Eradication. Disponível em: $<w w w . u n e p . o r g / g r e e n e c o n o m y>$. Acesso em 13 set.2013.

26. United Nation Environment Program. 2012. Capacity Development for Clean Development Mechanism - CDM/JI Pipelines. Disponível em <http://www.cd4cdm.org/CDMJIpipeline.htm z. Acesso em 20 jul.2012.

27. UNFCCC, United Nation Framework Convention on Climate Change. 2012. Clean Development Mechanism (CDM). Disponível em: <http://unfccc.int/Quioto_protocol/mechanisms/clean_development_mechanism/items/27 18.php>. Acesso em 23 jul.2012.

28. UNFCCC, Nation Framework Convention on Climate Change. 2012. ACM0001: Flaring or use 
of landfill gas --- Version 13.0.0. Disponível em: <http://cdm.unfccc.int/methodologies/DB/EYUD9R1ZAUZ2XNZXD3HQH18OK3VWIV/view.ht $\mathrm{ml}$. Acesso em 31 ago.2012.

29. USEPA, United States United States Environmental Protection Agency. 1996. Turning a Liability into as asset: A Landfill Gas-to-energy Project Development Handbook.

30. United States Environmental Protection Agency. 1997. Feasibility assessment for gasto-energy at selected landfills in São Paulo, Brazil. Public Review Draft. EPA 68-W6-004.

31. LUCAS, N.D.; MELO, A.S.S.A. Evidências do Protocolo de Quioto no Brasil: Uma análise exploratória descritiva. Revista Iberoamericana de Economía Ecológica, v. 16, p. 33-48, 2011.

32. FRIBERG, L. Varieties of carbon governance: The clean development mechanism in Brazil-a success story challenged. The Journal of Environment \& Development, v. 18, n. 4, p. 395-424, 2009.

33. DECHEZLEPRÊTRE, A.; GLACHANT, M.; MÉNIÈRE, Y. Technology transfer by CDM projects: A comparison of Brazil, China, India and Mexico. Energy policy, v. 37, n. 2, p. 703-711, 2009.

34. AMINI, H.R.; REINHART, D.R.; NISKANEN, A. Comparison of first-order-decay modeled and actual field measured municipal solid waste landfill methane data. Waste Management, 2013.

35. CORDEIRO, S. A.; SOUZA, C.C.; MENDOZA, Z.M.S.H.; SILVA, M.L. Etapas e custos dos projetos de mecanismo de desenvolvimento. Revista Agrogeoambiental, v. 2, n. 1, 2010.

36. IIED - The International Institute for Environment and Development. SSN - South South North Carbon Finance Guide for Task Team Leaders. Washington, DC: Carbon Finance Unit / World Bank, 2009. Available: http://siteresources.worldbank.org/INTCARBONFINANCE/Resources/TTL_guide_cd.pdf. Access: 20 Sep 2013.

37. YIN, R. K. Estudo de caso: planejamento e métodos. 2. ed. Porto Alegre: Bookman, 2001. 